\title{
Green Design of Modular Floating Structures
}

Modiga Alina, Popescu Gabriel

\begin{abstract}
This paper proposes a solution for the extension of the promenade and entertainment area, the green arrangement of the lower Danube river bank in Galati.

For the extension of the seafront width with cycle and roller tracks, alternating with paths for the promenade and creating areas for recreation activities with the maintenance of the existing green spaces, the solution of floating structures was chosen. An autonomous module that has been drawn and modeled 3D in Punch Home Design in various design forms, so as to allow it to be assembled in various positions and interconnect the modules between them.

Hydrodynamic calculations of the module positioned differently from the shore were made in XFlow Module (SolidWorks). The study reveals the two-fold role of the structures: extension of the promenade green areas and control of the currents that influence the erosion phenomenon (protection) the left bank of the Danube and the natural dredging of the river's bottom

The results obtained can stand at the bottom of some feasibility studies ordered by the urbanism committee of the municipality.
\end{abstract}

Keywords-Danube, modular, structures, promenade, solutions, analysis.

\section{Introduction}

In the summer of 2015, besides the Danube's share dropping, an island appeared on the Danube, along the Danube bank, next to Galati city. Although this island is out of the waterway, the appearance of this formation, whenever it decreases the level of the river, raises a series of questions about the risks of its expansion and affecting the width or depth of the navigable zone of the area.

The study of coastal currents in that area and study of river flow along the bank and around some floating structures can provide important information on the prognosis of alluvial deposition. Using these studies, various solutions can be proposed for maintaining the sailing line, by placing floating structures that lead to controlled and directed deposition of alluviums. Directed and controlled deposition of alluviums can, be one of the actions designed to maintain the navigable waterway. This can be a preferred solution to classic dredging that involves a significant technical effort, high costs and the destruction of the ecosystem that has formed in the area.

The placement of modular floating structures along the bank is a solution for the controlled and directed deposition of alluviums in other areas than in the direction of the navigable channel.

Modiga A., Popescu G..

"Dunarea de Jos" University of Galati

Romania

\section{Problem Formulation}

\section{A. Proposal for solutions}

The authors of this paper propose floating modules in the form of circle sectors of 60 degrees. These modules can be combined in multiple variants. The geometrical solutions for assembling these modules and their location on the left bank of the Danube will be able to achieve two purposes. Expansion of the promenade areas on the water, but especially the control of alluvial deposition and bank protection. Assembling multiple modules will accomplish a floating unit type.

This study was initiated at the request of local authorities to identify architectural proposals that are the elements of a call for tender for a feasibility project. The authors of this article propose the study of two modular assemblies in three variants:

1. a geometric unit consisting of three modules, with a semicircle axis;

2. a succession of three semicircular units;

3. a complex unit consisting in five modules.

Each of these variants involves both the architectural proposal and the study of the influence on the bank of the river.

\section{Computer Method}

The proposal made by the authors required the use of two CAD applications. Making 3D architectural models was through using Punch Home Design. In terms of fluid flow study around the proposed variants, SolidWorks was used.

\section{A. 3D architectural modeling}

The 3D architectural models involved the modeling of the upper and lower cliffs of the Danube in the city of Galati.

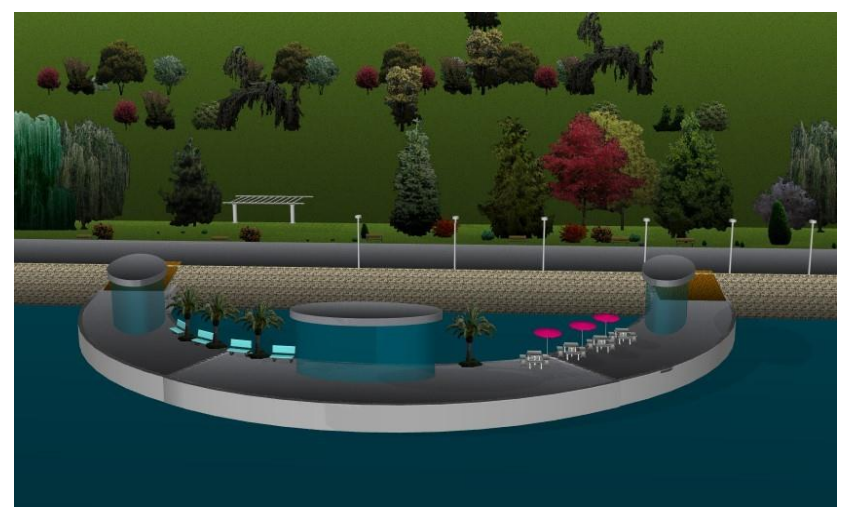

Figure 1. 3D modeling for a unit 
Proc. of the Sixth International Conference on Advances in Civil, Structural and Environmental Engineering - ACSEE 2017. Copyright ( $)$ Institute of Research Engineers and Doctors. All rights reserved.

ISBN: 978-1-63248-139-9 doi: 10.15224/ 978-1-63248-139-9-31

In this virtual ensemble the study variants with the design proposals were placed. Each module is designed to be energetic autonomous.

It was considered that in the variant of floating modules assembling there is a unit and from the point of view of the arrangement, the area of public eating and relaxation.

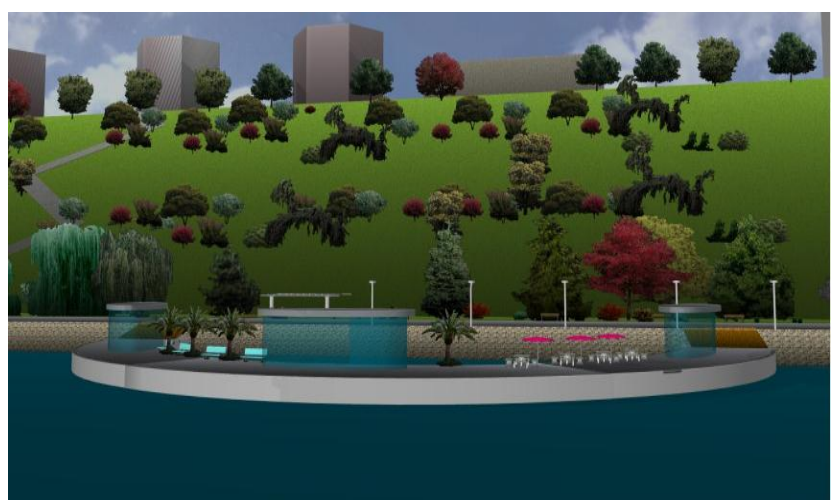

Figure 2. 3D modeling for a unit (with upper cliff)

Figures 1, 2, 3 and 4 show the proposed 3D urban architectural environment.

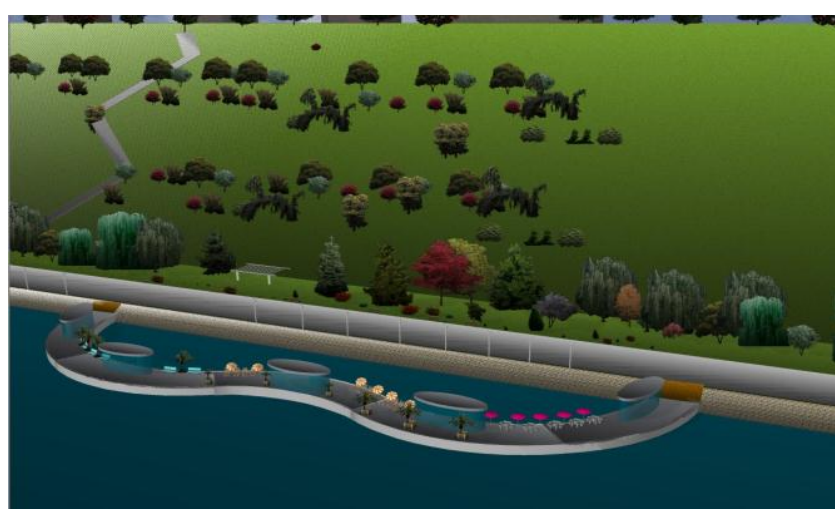

Figure 3. 3D modeling for a complex unit

The closed, glazed structural elements of these modules are provided with photovoltaic panels to ensure the autonomy of lighting and the use of public catering equipment.

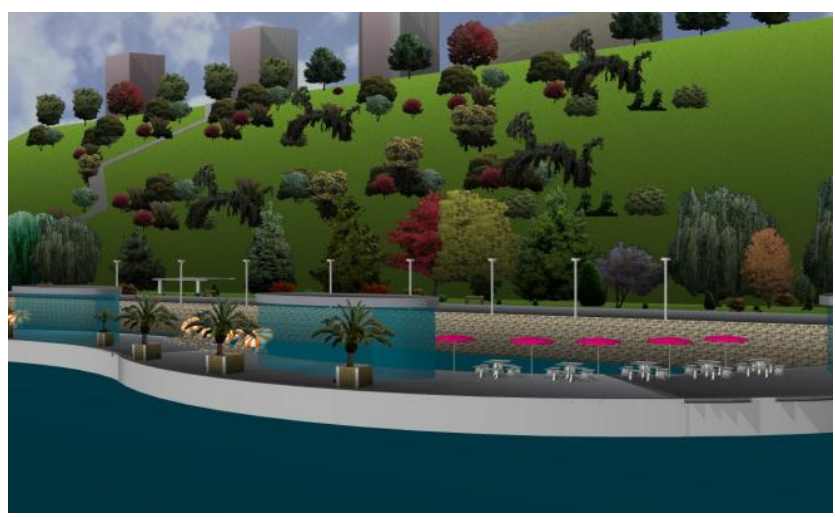

Figure 4. 3D modeling for a complex unit (with upper cliff)

\section{B. Modeling C.F.D.}

The Computational Fluid Dynamics analyses of the flow in various geometrical and geographical areas are done by the
XFlow module of the SolidWorks program. This module allows:

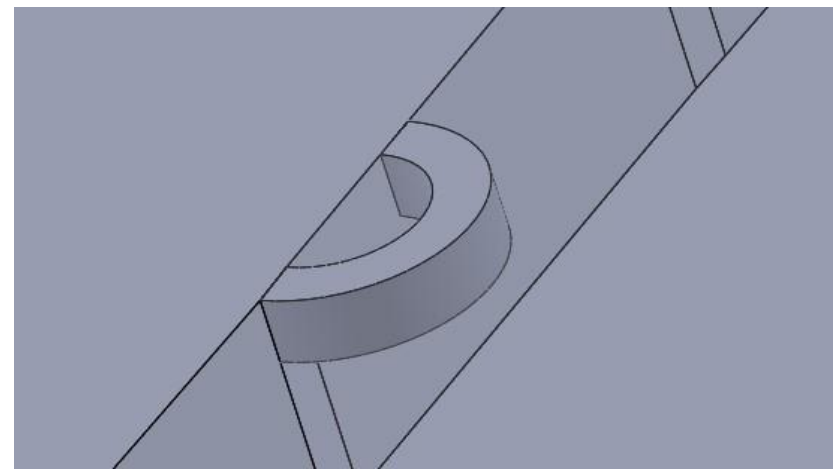

Figure 5. 3D modeling for a unit (3 modules)

geometry modelling in the fluid domain (Fig. 5, 6 7).; fluid characteristics selection; inlet and outlet boundary conditions [1] ; flow analysis [2], [3]; post-processing of the numerical results.

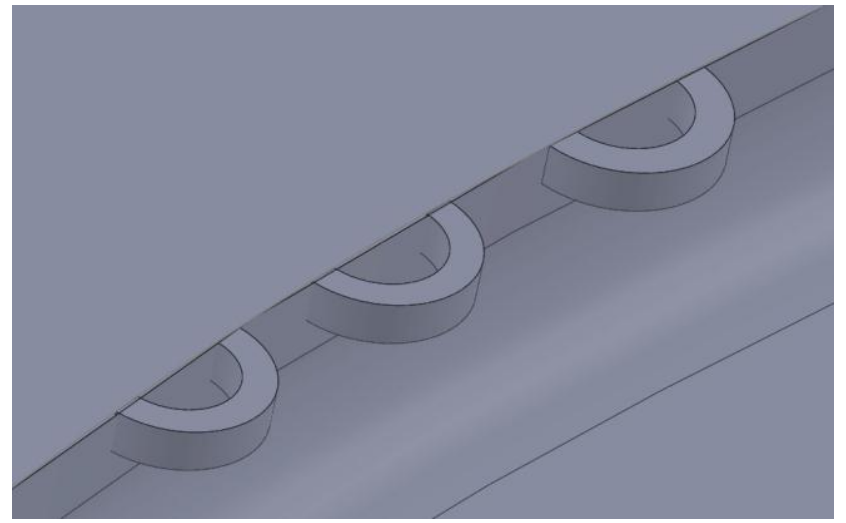

Figure 6. 3D modeling for three units

Figure 5 contains the unit number one. A unit with three modules.In figure six is the combination of three units, located approximately equidistant.

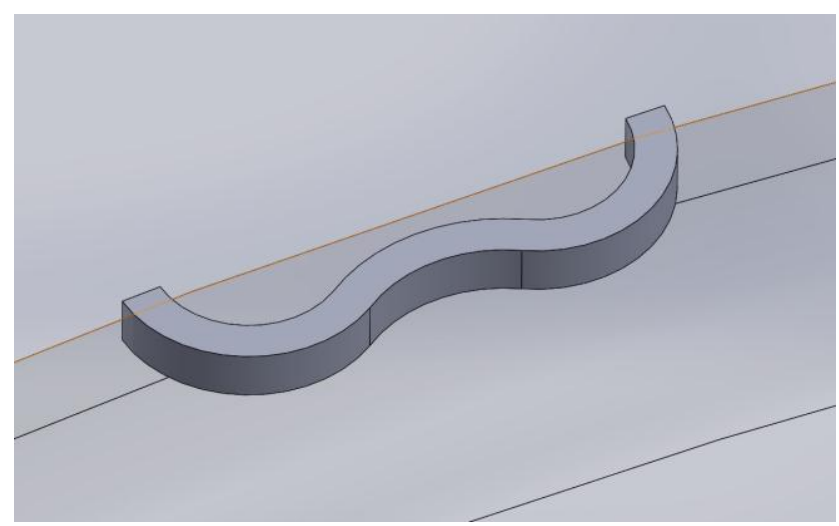

Figure 7. 3D modeling for a combination of units

In figure seven is the $3 \mathrm{D}$ model corresponding to the variant of the complex module assembly. 
Proc. of the Sixth International Conference on Advances in Civil, Structural and Environmental Engineering - ACSEE 2017. Copyright $(\odot$ Institute of Research Engineers and Doctors. All rights reserved.

ISBN: 978-1-63248-139-9 doi: 10.15224/ 978-1-63248-139-9-31

\section{Numerical Results and Discusions}

The SolidWorks program offers the possibility of viewing current lines and stationary and quasi stationary velocity areas. These areas are important for the present study because they favor the deposition of sediments in the Danube bed. Spectral analysis of fluid flows in the vicinity of the left bank of the Danube can lead to a decision on the influence of the location of the floating units [4], [5].

Comments will be made on the speed distributions for Danube currents in three horizontal sections, the float level, the level of the bottom of the floating structure and one meter below it [6]

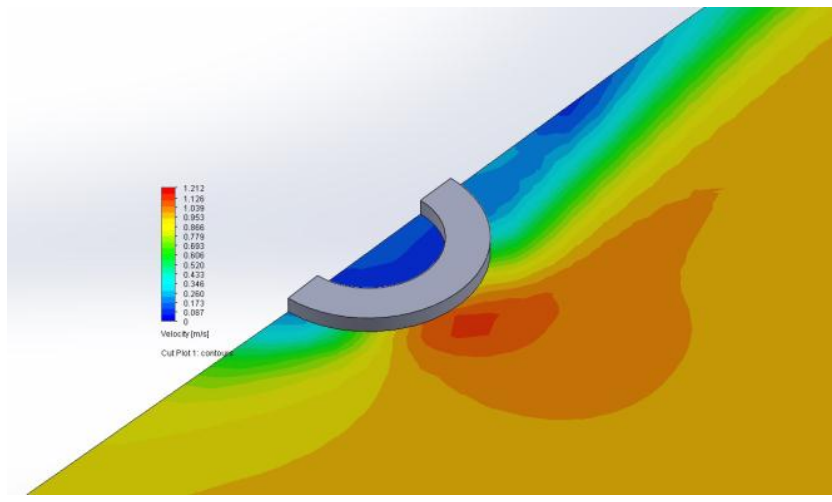

Figure 8. 1 unit - Floating - level speed spectrum

We're tracking the extreme areas of gears. The blue areas correspond to the stationary fields of the fluid velocities and the red ones are at high speeds of the river flow.

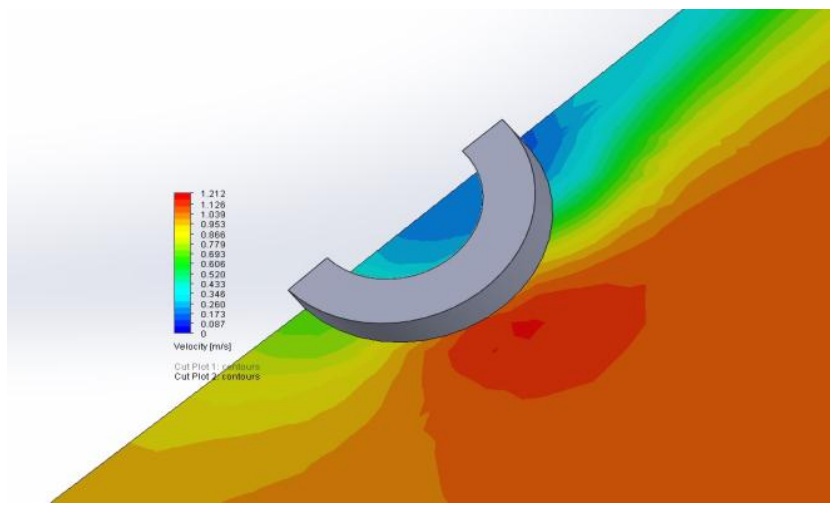

Figure 9. 1 unit - Bottom - level speed spectrum

Figure 8 shows the extended area of the stationary fluid field while the increased speed range is relatively narrow.

In figure 9, the reduced area of the fluid field is significantly reduced (compared to fig. 8) and the speed of the accelerated velocities increases (see the blue and red areas).

At one meter under the floating structure, the stationary speed zone disappears in favor of the increased velocity of the fluid currents (fig.10)

Figures 11, 12 and 13 show the results of C.F.D. in the variant of placing three successive floating units

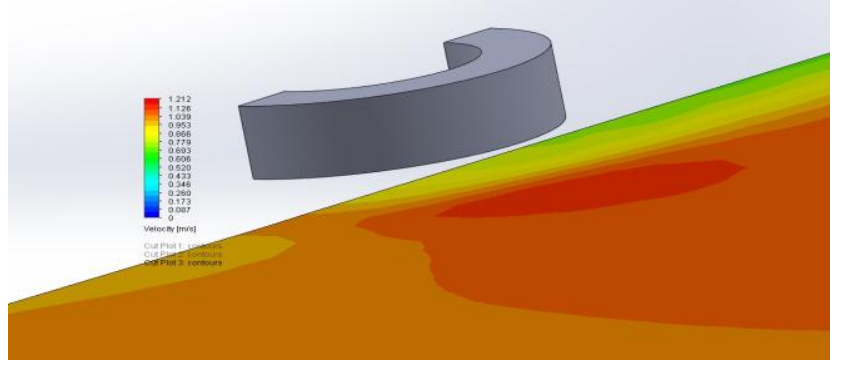

Figure 10. 1 unit - Under 1 meter from bottom - level speed spectrum

In this case, it is noted in Figure 11 the appearance of fluid fields with stationary speeds also between the floating units.

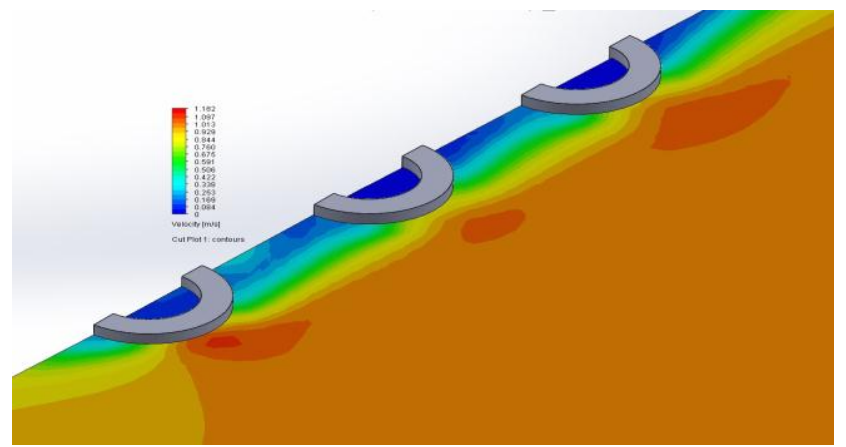

Figure 11. 3 units - Floating - level speed spectrum

This result leads to the idea that such an ensemble of floating units can protect the Danube's erosion shore for a significantly longer length than is shown in Figure 8.

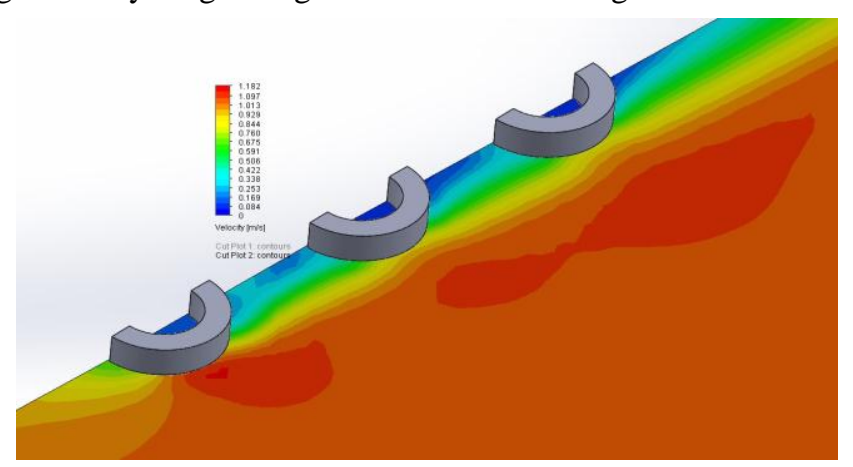

Figure 12. 3 units - Bottom - level speed spectrum

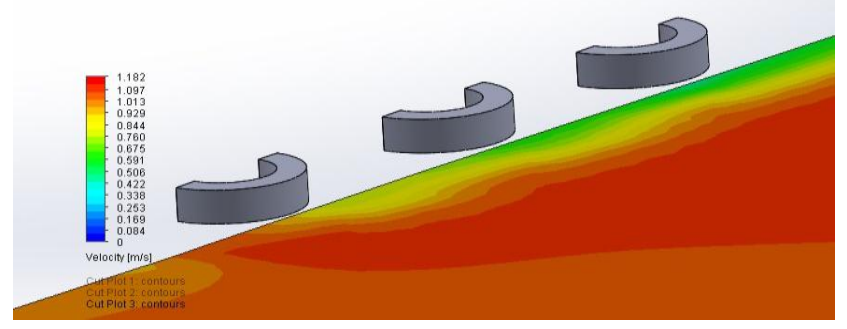

Figure 13. 3 units - Under 1 meter from bottom - level speed spectrum 
Areas with high velocities (red spots) of water currents increase with the depth of analysis as in Figures 11, 12 and 13.

If the areas with stationary speeds of the river currents protect the banks, the areas corresponding to the elevated speeds drain the bottom of the Danube.

Extending the red areas from Figure 11 to Figure 13 allows the appreciation of a floating body assembly in this arrangement to help drain the river bottom in the area of location.

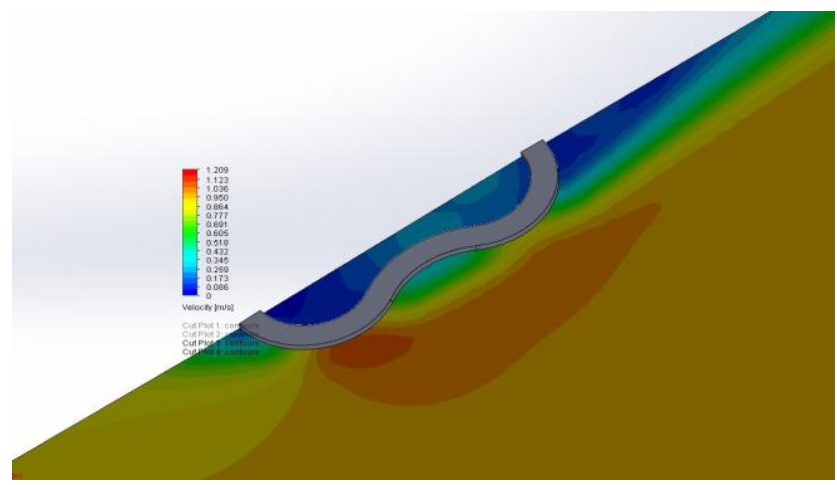

Figure 14. complex unit - Floating - level speed spectrum

In the next set of three figures $(14,15,16)$ are presented the results of the gear field distributions for the complex module assembly in the three horizontal sections, the float level, the bottom level and one meter below the bottom level

The area of stationary speeds (blue zone) in Figure 14 is noticeable inside and beyond the assembly.

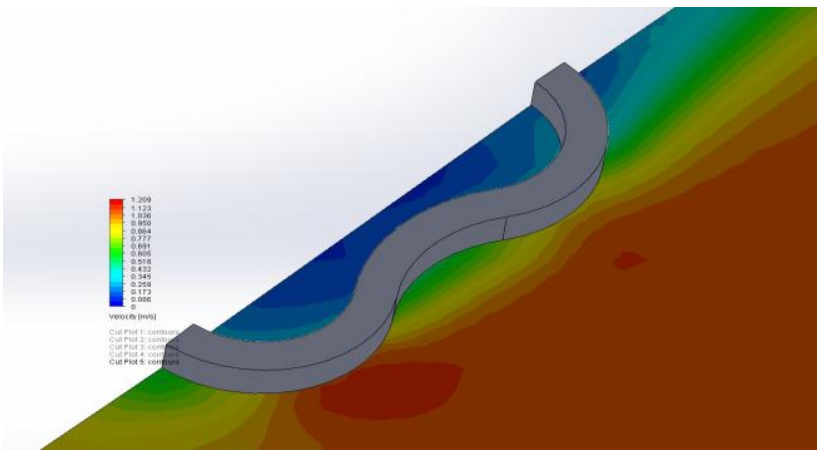

Figure 15. complex unit - Bottom - level speed spectrum

The fluid velocity spectra in figure 15 , highlights the shrinkage of the shore protection area in favor of increasing the areas of increased velocities.

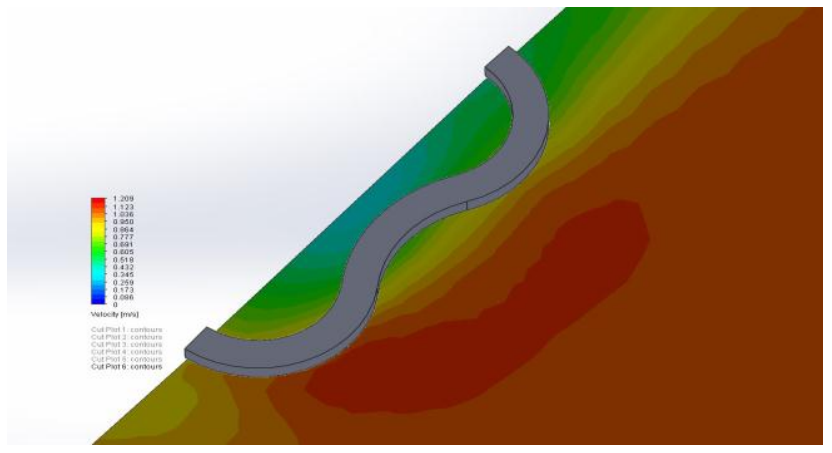

Figure 16. complex unit - Under 1 meter from bottom - level speed spectrum
Increasing the velocity of the fluid flows in the corresponding section of the bottom of the floating assembly is natural as a result of the reduction of the flow section

This phenomenon intensifies with the decrease of the depth of the analyzed section (fig. 16).

\section{v. Conclusions}

From the perspective of the bank of the Danube bank and the drainage of the bed of the river bed, the results analyzed in this paper highlight the fact that the singular units (Figures 8, $9,10)$ respond locally to these conditions.

The location on the Danube bank of a complex ensemble made of floating modules, with the results of the analysis presented in the series of Figures 14, 15, 16, leads to the conclusion that the protected area of the bank is in front of the assembly and downstream of it.

The analysis of the high flow velocity areas in the three sets of analyzes points out that the whole of a succession of floating units (fig. 6) generates a phenomenon of natural dredging of the river bed near the bank.

This study opens new research directions on the buoyancy of modules and assemblies. Structured structural solutions are in the attention of the authors, the division of floating units and the design of ballast tanks. The module architecture is the subject of a future study. Another proposed topic is the design of a floating module assembly system.

\section{References}

[1] Lower Danube River Administration AFDJ., Bathymetric and velocity measurements on the Danube river, , Galati, Romania, 2017;

[2] Baranya, S.; Jozsa, J. Flow analysis in river Danube by field measurement and 3D CFD Turbulence modeling, Periodica polytechnica ser. civ. eng. 50(1): 57-68,2006.;

[3] Baranya, S.; Jozsa, J., Investigation of Flow around a Groin with a 3D Numerical Model. In Proceedings II. PhD CivilExpo. Budapest University of Technology and Economics, Budapest, 2004.;

[4] Rusu E., Modelling of wave-current interactions at the mouths of the Danube, Published online: 4 December JASNAOE, 2009;

[5] Strechie Sliwinski C., Jugaru Tiron L., Szobotka S., Dimitriu R., Pop C I., Viteze de curenţi şi debite ale apelor Dunării măsurate cu ajutorul Sontek Riversurveyor A, 2008, http://www.geoecomar.ro/website/publicatii/supliment2008/3.pdf.

[6] Popescu, G.; Modiga, A., The influence of barges anchorages on the navigable channel, SGEM, Viena 2017 